\title{
Mercado de tierras en la Comunidad Campesina de Miluchaca - Sapallanga 2019
}

\author{
Land market in the Peasant Community of Miluchaca - Sapallanga 2019
}

\author{
Francisca Huamán Pérez ${ }^{1}$ (D), Gualberto Poma Castellanos 2 (iD), Roberto Lider Churampi \\ Cangala ${ }^{3}$ ii
}

\author{
Cómo citar \\ Huamán Pérez, F., Poma Castellanos, G. y Churampi Cangala, R. L. (2021). Mercado de tierras en la Comunidad Campesina de \\ Miluchaca - Sapallanga 2019. Socialium, 5(1), 150, 162. https://doi.org/10.26490/uncp.sl.2021.5.1.577
}

${ }^{1}$ Magister en Responsabilidad, Universidad Nacional del Centro del Perú, Huancayo, Perú.

fhuaman@uncp.edu.pe Google Scholar

${ }^{2}$ Doctor en Gestión Pública y Gobernabilidad, Magister en Desarrollo Rural, Universidad Nacional del Centro del Perú, Huancayo, Perú. gpoma@uncp.edu.pe Google Scholar

${ }^{3}$ Magister en sistemas industriales y gestión empresarial, Universidad Nacional del Centro del Perú, Huancayo, Perú.

ROCHURAMPI@uncp.edu.pe Google Scholar

Arbitrado por pares ciegos Recibido: 04/05/2020 Aceptado: 05/12/20

\section{RESUMEN}

La investigación titulada: Mercado de tierras en la Comunidad Campesina de Miluchaca Sapallanga 2019, tuvo como objetivo Identificar los factores que facilitan la expansión del mercado de tierras en la Comunidad Campesina de Miluchaca - Sapallanga. El método general que guio la investigación es el científico, el tipo de investigación es básica, enfoque de investigación cualitativo, nivel de investigación descriptivo, diseño de investigación fenomenológico hermenéutico, las técnicas fueron el análisis documental, la entrevista semi estructurada y la observación. Encontrándose que la expansión de mercado de tierras obedece a la demanda de tierras de parte de los inmigrantes para la construcción de viviendas fundamentalmente, para ello los dueños en este caso los ofertantes primero sanearon las propiedades y en seguida van vendiendo lotizando estas tierras a precios que el mercado impone. Finalmente, se concluye en que el mercado de tierras en la Comunidad Campesina de Miluchaca se viene expandiéndose de manera rápida por la demanda de los inmigrantes y por oferta de los propietarios por necesidades económicas. Estas tierras para entrar en el mercado tuvieron que ser saneado legitimándose la propiedad privada a favor de los posesionarios.

Palabras claves: mercado de tierras; inmigración; emigración.

\section{ABSTRACT}

The research entitled: Land market in the Campesino Community of Miluchaca - Sapallanga 2019, aimed to identify the factors that facilitate the expansion of the land market in the Campesino Community of Miluchaca - Sapallanga. The general method that guided the research is the scientist The type of research is basic, qualitative research approach, level of descriptive research, hermeneutical phenomenological research design, the techniques were documentary analysis, semi-structured interview and observation. Finding that the expansion of the land market is due to the demand of land from immigrants for the construction of housing mainly, for this reason the owners in this case the bidders first sanitized the properties and immediately sell these lands at prices that the market imposes. Finally, it is concluded that the land market in the Campesino Community of Miluchaca has been expanding rapidly due to the demand of immigrants and the owners' offer due to economic needs. These lands to enter the market had to be cleared by legitimizing private property in favor of the possessors.

Keywords: land market; immigration; emigration. 


\section{Introducción}

La presente investigación titulada: Mercado de tierras en la Comunidad Campesina de Miluchaca Sapallanga 2019, ha sido abordado desde la sociología, el área de estudio está ubicada en el distrito de Sapallanga, zona sur del valle del Mantaro que, tiene una riqueza biodiversa del capital natural, en el presente siglo este territorio presenta una serie de cambios en los aspectos económicos, sociales, políticos, culturales y ambientales.

En ese contexto se presenta fuertemente el mercado de tierras: demanda y oferta de terrenos para la construcción de viviendas debido al crecimiento de la población inmigrante de las regiones de Huancavelica, Ayacucho, Cerro de Pasco, Huánuco y la sierra de Lima, provincia de Yauyos en todo el valle del Mantaro, estos inmigrantes son los que vienen comprando los terrenos. Por otro lado, es que los originarios lugareños miluchaquinos en un porcentaje mayor han inmigrado a la capital distrital de Sapallanga, Chilca, Huancayo, Selva Central, Lima y otras regiones, por lo que muchos de ellos van vendiendo terrenos lotizando, encontramos frente a un progresivo y sigiloso crecimiento de mercado de tierras en las áreas rurales, sin que los miembros de las juntas directivas puedan realizar acciones concretas (Huamán, 2017).

Para ello establecimos los objetivos, general explicar la expansión del mercado de tierras en la Comunidad Campesina de Miluchaca - Sapallanga 2018, específicos: explicar sobre el factor externo que viene propiciando el mercado de tierras en la Comunidad Campesina de Miluchaca - Sapallanga y explicar sobre el factor interno que viene propiciando el mercado de tierras en la Comunidad Campesina de Miluchaca - Sapallanga. El método general que guió la investigación es el científico, el tipo de investigación es básica, enfoque de investigación cualitativo, nivel de investigación descriptivo, diseño de investigación fenomenológico hermenéutico, los informantes claves fueron diez, las técnicas fueron el análisis documental, la entrevista semi estructurada y la observación.

En ese devenir se ha llegado a las conclusiones siguientes: 1) El mercado de tierras en la Comunidad Campesina de Miluchaca se viene expandiéndose de manera rápida por la demanda de los inmigrantes y por oferta de los propietarios por necesidades económicas. Estas tierras para entrar en el mercado tuvieron que ser saneado legitimándose la propiedad privada a favor de los posesionarios, 2) En la Comunidad Campesina de Miluchaca el factor externo que viene propiciando el mercado de tierras es la demanda de los inmigrantes de terrenos para la construcción de sus viviendas, puesto que los terrenos en Chilca, Huancayo y El Tambo ya no es accesible por el alto costo y falta de espacios. La poca oferta y el alto costo de los terrenos y viviendas en la ciudad viene expulsando a los inmigrantes a demandar lotes de tierras en las áreas periféricas de Huancayo para la construcción de sus viviendas y 3 ) En la Comunidad Campesina de Miluchaca el factor interno que 
viene propiciando el mercado de tierras es la necesidad económica y la fuerte emigración de los propios lugareños. Estas tierras para entrar al mercado, entraron al desmembramiento y formalización en las instancias de las notarías y el Registro Público de la ciudad de Huancayo, quedando expeditos para poder vender a los que demandan comprar, así la confianza llega para los demandantes y ofertantes, pero los predios subieron de precio.

\section{Método}

El método general es científico, Bunge (2010) “...es un procedimiento que se aplica al ciclo entero de la investigación" (p. 24) y siendo el método específico narrativo. Respecto al tipo Hernández, Fernández y Baptista (2016) afirma "La investigación puede cumplir dos propósitos fundamentales: a) producir conocimiento y teorías (investigación básica) y b) resolver problemas prácticos (investigación aplicada)" (p. XXVI). De estos elementos la presente investigación se relaciona con la primera. El nivel en que abordamos y damos cuenta los resultados es descriptivo explicativo narrativamente escrita.

El diseño exploró, describió y comprendió a los compradores y vendedores de terrenos, o sea abordamos directamente a los actores de manera directa, nos referimos al uso del diseño fenomenológico hermenéutico. Teniendo en consideración que se desarrolló una investigación con enfoque cualitativo, las unidades de análisis fueron seleccionados y comprendidos en actores como autoridades, compradores y vendedores de terrenos en el espacio territorial comunal. Finalmente, las técnicas que utilizamos fueron la observación, la entrevista y la revisión documental cada uno con sus instrumentos de investigación respectiva.

\section{Resultado}

\section{Aspectos generales}

La comunidad campesina de Miluchaca, se encuentra ubicado al sur del valle del Mantaro distrito de Sapallanga, limita por el norte con la comunidad campesina de La Punta, por el sur con la comunidad campesina de Sapallanga, por el este con la ex Sais Cahuide y por el oeste con La Punta. Tiene un clima templado, con flora y fauna diverso, con acceso vial por carretera y caminos de herradura, cuenta con cinco barrios Manzanares, La Libertad, Florida, Centro y José Olaya.

Los pobladores se dedican a la actividad agrícola, ganaderas, comercio y transporte, históricamente está relacionado con la historia de la comunidad campesina de Sapallanga inicialmente y posteriormente con la historia de la comunidad campesina de La Punta. 


\section{Expansión del mercado de tierras en la Comunidad Campesina de Miluchaca - Sapallanga}

Antes de la formalización de la propiedad rural a partir de las reformas estructurales de libre mercado de la década del 90 del siglo pasado, el acceso a la tierra en la comunidad campesina de Miluchaca se otorgaba de diversas formas como podemos establecer en la siguiente tabla:

\section{Tabla 1}

Derecho sobre la tierra

\begin{tabular}{ccc}
\hline & Derecho sobre la tierra & Documento \\
\hline Acceso & Por herencia & Testimonio familiar \\
Por compra & Notarial y/o Juez de Paz \\
Por entrega comunal & Libro de actas \\
Por alquiler & Contrato notarial \\
Por préstamo & Contrato ante juez de paz \\
Al partir & Contrato ante juez de paz \\
\hline
\end{tabular}

El acelerando mercado de tierras en la comunidad campesina de Miluchaca - Sapallanga viene siendo impulsado por tres factores como la 1) Constitución Política del Perú en su artículo 58 que promociona la iniciativa privada de manera libre, 2) los principios básicos de una economía liberal como la propiedad privada, mercado libre, la libre competencia, el libre comercio y la libertad de elección, y 3) la inexistencia de un plan de desarrollo puntual urbano en el espacio territorial del distrito de Sapallanga, la relación que existe entre los elementos de las comunidades campesinas y el Estado se encuentra mediada por los patrones de tenencia de la tierra (Gutierrez y Garcia 2016), son realmente los escenarios para que se venga acelerando el proceso de compra y venta de tierras.

Para el análisis de la expansión del mercado de tierras en la comunidad, sistematizamos recurriendo a la revisión documental con respecto al saneamiento físico de los predios rurales en la comunidad campesina de Miluchaca, así pudimos sistematizar respecto a la extensión territorial que cada propietario posee en la parte urbana no excediendo los 2 mil metros cuadrados, la existencia de recursos naturales ya sea este el suelo agrícola y tiene el carácter de privado (Lima y Ignacio 2016).

El proceso de formalización de la propiedad empezó con el empadronamiento de los terrenos ocupados por los posesionarios comuneros de manera informal en la parte urbana de Miluchaca, porque la Ley 28687 establece en el artículo 1. Que el proceso de formalización de la propiedad informal, es para acceder al suelo para uso de vivienda de interés social orientado a los sectores de menores recursos económicos y establece el procedimiento para la ejecución de obras de servicios básicos de agua, desagüe y electricidad. Estas tierras que han sido levantadas con fines del catastro 
rural agrario en Miluchaca fueron ubicados en sectores y manzanas, todos por su puesto ubicadas en el área de la comunidad, los que podemos mostrar en las siguientes tablas:

\section{Tabla 2}

Saneamiento físico de los predios rurales por manzanas en la Comunidad Campesina de Miluchacasector 1

\begin{tabular}{|c|c|c|}
\hline MANZANA & LOTES & AREAS \\
\hline$A$ & 1 & 1060.50 \\
\hline B & 8 & 7982.50 \\
\hline C & 1 & 560.00 \\
\hline D & 3 & 3641.20 \\
\hline$E$ & 6 & 629.70 \\
\hline$F$ & 5 & 3333.20 \\
\hline G & 6 & 2628.30 \\
\hline $\mathrm{H}$ & 2 & 638.50 \\
\hline I & 6 & 4754.70 \\
\hline J & 2 & 506.70 \\
\hline K & 3 & 1652.60 \\
\hline $\mathrm{L}$ & 18 & 9286.90 \\
\hline M & 16 & 3714.50 \\
\hline $\mathrm{N}$ & 2 & 582.70 \\
\hline 0 & 4 & 2491.60 \\
\hline$P$ & 18 & 5748.20 \\
\hline$Q$ & 1 & 1837.40 \\
\hline $\mathrm{R}$ & 16 & 5828.60 \\
\hline$S$ & 24 & 8123.30 \\
\hline $\mathrm{T}$ & 1 & 212.40 \\
\hline U & 14 & 8676.50 \\
\hline V & 10 & 4672.30 \\
\hline W & 12 & 3133.90 \\
\hline TOTAL 23 & 179 & 81696.20 \\
\hline
\end{tabular}

El mercado de tierras tiene su inicio con la existencia de elementos compradores y vendedores de las tierras (Marcelo 2019), para el proceso de expansión de la compra y venta de las tierras en el territorio de la comunidad, los comuneros posesionarios desde sus ancestros han venido formalizando con COFOPRI esas tierras para poder vender legalmente a quienes demandan, los demandantes generalmente son ciudadanos emigrantes de pueblos vecinos y/o regiones vecinas. 


\section{Tabla 3}

Saneamiento físico de los predios rurales por manzanas en la Comunidad Campesina de Miluchacasector 2

\begin{tabular}{lcc}
\hline MANZANA & LOTES & ÁREAS \\
\hline A & 21 & 13864.20 \\
B & 4 & 2343.70 \\
C & 4 & 1444.10 \\
D & 5 & 3717.30 \\
E & 4 & 12491.50 \\
F & 3 & 2047.00 \\
G & 3 & 3366.30 \\
H & 6 & 2038.30 \\
I & 4 & 4130.90 \\
J & 5 & 198.90 \\
K & 1 & 369.40 \\
L & 1 & 9724.90 \\
M & 6 & 1271.40 \\
N & 3 & 1599.30 \\
O & 4 & 2029.90 \\
P & 4 & 3877.20 \\
Q & 4 & 2771.90 \\
R & 4 & 2672.20 \\
S & 4 & 771.30 \\
T & 8 & 3105.60 \\
\hline TOTAL 20 & 2 & 74474.80 \\
\hline & 3 & \\
\hline
\end{tabular}

Estas tierras desmembradas y formalizadas en las instancias de las notarías y el Registro Público de la ciudad de Huancayo quedan expeditos para poder vender a los que demandan comprar, antes existía desconfianza de parte de los demandantes puesto que los terrenos no tenían amparo legal, ahora estos predios subieron de precio.

Factor externo propicia el mercado de tierras en la Comunidad Campesina de Miluchaca - Sapallanga La inmigración de poblaciones del sur del valle del Mantaro nos referimos a los pobladores de Huancavelica, Ayacucho y Apurímac son quienes vienen demandando terrenos para la construcción de sus viviendas, puesto que los terrenos en Chilca, Huancayo y El Tambo ya no es accesible por el alto costo y falta de espacios. La poca oferta y el alto costo de los terrenos y viviendas en la ciudad 
viene expulsando a los inmigrantes a demandar lotes de tierras en las áreas periféricas de Huancayo para la construcción de sus viviendas.

"Ahora mayormente están comprando al pie de la pista para construir sus casas, los que compran no solo son del lugar, sino mayormente son de otros lugares, de alguna manera el precio ha subido, pero pienso el precio debe ser mucho más, ahora viene subiendo con nuestros títulos de propietario" (G. Vila, comunicación personal, 12 de setiembre del 2019).

La demanda de tierras en el sur del valle del Mantaro es fundamentalmente para acceder un espacio para la construcción de viviendas, los predios que están ubicados al pie de la pista o calles importantes en la parte periurbana de la comunidad de Miluchaca viene subiendo en su costo, puesto que tienen título de propiedad otorgado por la SUNARP y cuenta con servicios básicos de agua, luz y desagüe, y del mismo modo este centro periurbano cuenta con servicios de transporte y otros, por todo esto las personas interesadas tienen atracción para comprar estas tierras.

"Compramos un terrenito de 250 M2, en Huancayo ya es muy caro ya no podemos alcanzar, pero Miluchaca está muy cerca hay combis cada 5 minutos o si quieres taxi a cada rato, además es un lugar tranquilo" (F. De La Cruz, comunicación personal, 24 de setiembre del 2019).

El entrevistado refiere que los servicios de transporte de combi o taxi de Miluchaca a Huancayo o viceversa son muy eficientes para poder ir a trabajar, estudiar y hacer compras en el mercado, por esa facilidad y cercanía con la ciudad de Huancayo y la capital del distrito de Sapallanga a la que pertenece Miluchaca fueron la atracción para la compra del terreno para que pudiera construir una vivienda y vivir.

"Yo soy de Pazos Huancavelica, compré esta casa porque el dueño se fue a Lima, ya vivo 4 años, Miluchaca es un lugar hermoso y tranquilo por eso mucha gente vienen comprando terrenos y casas, hay mucha facilidad para ir a trabajar a Huancayo" (J. Quilca, comunicación personal, 19 de setiembre del 2019).

Las oportunidades para comprar terrenos o casas están en base a la oferta que vienen promocionando los dueños o compradores a través de avisos en periódicos, radios y en paneles ubicando el número de celular, la dirección y la extensión. Los compradores generalmente demandan entre $100 \mathrm{~m} 2$ a $150 \mathrm{~m} 2$, porque en su mayoría las personas que buscan terrenos de escasos recursos económicos.

"Los terrenos están muy caritos, pero todavía se puede comprar, en la parte céntrica los terrenos cuestan más, pero en la parte de las chacras están todavía menos, pero no tiene 
desagüe, luz y agua, pero más adelante llegará, para eso la comunidad debe aperturar las calles, mientras solo tenemos que mantener como está" (E. Poma, comunicación personal, 5 de setiembre del 2019).

Las personas demandantes de tierras para viviendas se someten al mercado, porque esos bienes inmuebles son de propiedad privada como mercancía, actualmente puede venderse y comprarse libremente, la limitante para los compradores es el dinero, porque los terrenos ubicados en la parte céntrica no están menos de 600 a 800 soles el m2, en las áreas periféricas esta aproximadamente entre 200 a 300 soles el m2.

"Como tiene título de propiedad este terreno que compré, con esa garantía saqué un préstamo del banco con eso pagué la compra de este terreno, ahora voy pagando poco a poco, pero es la única forma de tener algo en la vida" (J. Peralta, comunicación personal, 20 de setiembre del 2019).

Los terrenos de Miluchaca por tener título de propiedad, por estar cerca de la ciudad, por tener los servicios de transporte y tener los servicios básicos en la parte periurbana tienen un precio mayor, para poder pagar ese precio alto los interesados en comprar solicitan al banco para poder financiar dejando como garantía el predio.

"Yo, compré un terreno de $680 \mathrm{~m} 2$ de mi primo que se fue a Lima en Manzanares, aquí siembro, pero no tiene riego por eso mi vendió un poco cómodo, además me vendió con un documento simple" (L. Porras, comunicación personal, 9 de setiembre del 2019).

Esto refleja el desarrollo de compra y venta de tierras en Miluchaca está acelerando la transformación de las áreas agrícolas periurbanas y del mismo modo va generándose nuevas relaciones sociales en ese proceso, donde el territorio experimenta el ingreso de 1) intermediarios inmobiliarios, 2) los hijos de los propios campesinos convirtiéndose en compradores inmobiliarios y 3 ) personas extrañas compradores, los dos primeros compran terrenos solo fines de lotizar terrenos.

\section{Factor interno propicia el mercado de tierras en la Comunidad Campesina de Miluchaca - Sapallanga}

Los lugareños de Miluchaca que lograron titular sus propiedades a través de COFOPRI, actualmente vienen ofertando lotes de tierras para viviendas, las razones de venta que pudimos establecer son: 1) por emigrar a otras regiones o internamente a la capital de la región Junín, 2) para invertir en la educación de sus hijos, 3) Por salud, 4) para invertir en algún negocio, 5) compra de carros, 6) para poder mejorar su vivienda, 7) para el matrimonio de sus hijos y 7) para la fiesta. De todos, el primero 
tiene mayor peso, puesto que la mayoría de los lugareños van emigrando a la capital de la República, capital de la región Junín - Huancayo y Selva central.

“Nuestros paisanos están vendiendo sus terrenos sobre todo hacia las entradas de la carretera y en algunas calles céntricas al pueblo, porque la gente busca con agua, desagüe y luz, lo malo es que son gente extraña que han llegado a generar problemas de robo y generan mucha basura, antes Miluchaca era más tranquilo y limpio" (J. Relicario, comunicación personal, 18 de setiembre del 2019).

Los pobladores a futuro vislumbran las consecuencias que vendrá con la llegada de extraños, dicen que vendrán los problemas sociales de limpieza pública, la delincuencia y entre otros, preocupación que surge por los residentes permanentes, pero los emigrantes tienen necesidad de vender para poder invertir en el lugar de destino, los que venden en su mayoría ya no retornan, puesto que ya radican fuera de Miluchaca. Solo retornan en las fiestas festivas como el 16 de setiembre, fiesta de la Virgen de Cocharcas y el 26 de enero aniversario de la comunidad.

“Por necesidad vendí hace 6 años atrás un terreno de extensión de 280 M2 al pie de la pista, en ese año el metro a 100 soles ahora viene costando 700 o 800 soles el M2, esos terrenos ya tienen título de propiedad por eso se elevó el precio, porque también mucha gente ahora busca terreno para casa por eso sube el precio, esto va seguir subiendo" (B. Saturnino, comunicación personal, 12 de setiembre del 2019).

Para los vendedores es una ventaja la cercanía a la ciudad, como estable Kautsky la renta diferencial tiene que ver entre una de sus características con el lugar con relación a la distancia del mercado, el derecho de propiedad sobre la tierra genera un monopolio con libertad de decisión sobre su destino a través del cual puede generarse un usufructo adquiriendo un determinado valor de acuerdo con el proceso capitalista de producción que asume (Diaz, 2016), siendo una ventaja realmente que beneficia a los ofertantes de los terrenos en los diferentes espacios del valle del Mantaro, específicamente en Miluchaca.

“Antiguamente más se trabajaba la chacra, por eso se quería más chacras, en estos tiempos los jóvenes ya no quieren trabajar la chacra, los jóvenes actualmente ya son profesionales, trabajan como transportistas, negocios en las ciudades como Lima o Huancayo por eso también seguro que vienen vendiendo sus herencias" (P. Floriano, comunicación personal, 12 de setiembre del 2019).

Para los miluchaquinos el motivo principal de salida de su lugar de origen es lo económico, siendo una de las causas muchas veces determinante en el proceso migratorio, relacionado con la búsqueda de mejores condiciones laborales e ingresos para el logro de una vida mejor individual y familiar. El 
fenómeno de la emigración está asociado a las disparidades de ingreso entre distintas regiones y dentro de una misma región, existe una relación directa entre desarrollo socioeconómico y subdesarrollo y migración. Es la pobreza y la falta de oportunidades económicas, sociales de la localidad, que obliga a los emigrantes a migrar hacia otros lugares en busca de un mejor porvenir para ellos y sus familiares, desarrollándose una movilidad social.

"Creo ha sido importante la titulación de nuestras tierras por COFOPRI, eso nos está permitiendo que podemos vender nuestras tierras a un precio regular, la gente también busca algo seguro, la titulación es muy importante tanto para el vendedor como para el comprador" (D. Damas, comunicación personal, 12 de setiembre del 2019).

Este proceso de titulación en términos generales en la comunidad de Miluchaca es el paso de la apropiación colectiva a la apropiación privada que viene produciéndose al interior desde hace mucho tiempo como consecuencia del proceso de penetración del capital en el campo. Este proceso ha empezado en la parte de la zona urbana, tendiendo al acaparamiento de tierras, aunque según el régimen de tenencia y uso de la tierra está prohibido el acaparamiento de tierras dentro de la comunidad.

\section{Discusión}

\section{Factores externos que influye en el mercado de tierras en la Comunidad Campesina de Miluchaca} - Sapallanga.

En la investigación establecimos que los inmigrantes del sur del valle del Mantaro nos referimos a los pobladores de Huancavelica, Ayacucho y Apurímac son quienes vienen demandando terrenos para la construcción de sus viviendas fundamentalmente, puesto que los terrenos en Chilca, Huancayo y

El Tambo ya no es accesible por el alto costo y falta de espacios. La poca oferta y el alto costo de los terrenos y viviendas en la ciudad viene expulsando a los inmigrantes a demandar lotes de tierras en las áreas periféricas de Huancayo para la construcción de sus viviendas. Pero, para que ocurra lo que señalamos se legitima la propiedad privada y se utiliza para la compra y venta estas tierras como establece Carrera (2010) en el estudio realizado en Guatemala. De esto corrobora Katsky (1980) cuando dice la propiedad privada de la tierra a la tierra le convierte en mercancía, esta mercancía se compra y se vende, asimismo, Bauer (2003) manifestó la tierra siendo propiedad privada puede venderse y comprarse, eso es lo que ocurre en Miluchaca a partir de la formalización de la propiedad rural a partir de las reformas estructurales de libre mercado de la década del 90 del siglo pasado.

Del mismo modo establecemos que la demanda de tierras en el sur del valle del Mantaro es fundamentalmente para acceder un espacio para la construcción de viviendas, los predios que están 
ubicados al pie de la pista o calles importantes en la parte periurbana de la comunidad de Miluchaca viene subiendo en su precio, puesto que tienen título de propiedad otorgado por la SUNARP y cuenta con servicios básicos de agua, luz y desagüe, y del mismo modo este centro periurbano cuenta con servicios de transporte y otros, por todo esto las personas interesadas tienen atracción para comprar estas tierras. Pero esto viene generando una perdida sustancial de las tierras agrícolas en toda la periferia del centro urbano como dice Pimentel (2017) en su estudio realizado en Lima el año 2017.

Factor interno que influye en el mercado de tierras en la Comunidad Campesina de Miluchaca Sapallanga

Asimismo, en el resultado de la investigación establecimos que los lugareños de Miluchaca que lograron titular sus propiedades a través de COFOPRI, actualmente vienen ofertando lotes de tierras para viviendas, las razones de venta que pudimos establecer son: 1) por emigrar a otras regiones o internamente a la capital de la región Junín, 2) para invertir en la educación de sus hijos, 3) Por salud, 4) para invertir en algún negocio, 5) compra de carros, 6) para poder mejorar su vivienda, 7) para el matrimonio de sus hijos y 7) para la fiesta. De todos, el primero tiene mayor peso, puesto que la mayoría de los lugareños van emigrando a la capital de la República, capital de la región Junín Huancayo y Selva central. Para ello los propietarios que accedieron a la tierra por diversas modalidades legitimaron su título de propiedad otorgado por la SUNARP, porque para entrar al mercado estos bienes inmuebles debían estar registrados, como dice Carrera para tal efecto se legitimó la propiedad. Corroborando el resultado Vogelgesang (1998) expresó el título de dominio es el único que ofrece a los pequeños propietarios la posibilidad de utilizar la tierra como garantía para vender y para solicitar préstamos.

Por otra parte coincidiendo con Pimentel (2017) podemos manifestar que esto refleja el desarrollo de compra y venta de tierras en Miluchaca, el mismo que está acelerando la transformación de las áreas agrícolas periurbanas y del mismo modo va generándose nuevas relaciones sociales en ese proceso, donde el territorio experimenta el ingreso de 1) intermediarios inmobiliarios, 2) los hijos de los propios campesinos convirtiéndose en compradores inmobiliarios y 3) personas extrañas compradores, los dos primeros compran terrenos solo fines de lotizar terrenos. Terminamos parafraseando a De Soto (2000) el objetivo de los títulos fue necesario para incrementar la seguridad de la tenencia para que los propietarios tengan más posibilidades de vender y hacer inversiones. Finalmente, Zegarra (1999) dice el mercado es el mecanismo legítimo de asignación de tierras que requiere la sociedad. Esto implica que los propietarios de la tierra serán tratados social y jurídicamente como personas con plenos derechos de uso, disposición y alienación del recurso de 
acuerdo a su propia conveniencia y dentro de los marcos que la sociedad considere aceptables, por ello los propietarios de Miluchaca vienen ofertando la tierra como mercancía.

\section{Conclusión}

El mercado de tierras en la Comunidad Campesina de Miluchaca se viene expandiéndose de manera rápida por la demanda de los inmigrantes y por oferta de los propietarios por necesidades económicas. Estas tierras para entrar en el mercado tuvieron que ser saneado legitimándose la propiedad privada a favor de los posesionarios.

En la Comunidad Campesina de Miluchaca el factor externo que viene propiciando el mercado de tierras es la demanda de los inmigrantes de terrenos para la construcción de sus viviendas, puesto que los terrenos en Chilca, Huancayo y El Tambo ya no es accesible por el alto costo y falta de espacios. La poca oferta y el alto costo de los terrenos y viviendas en la ciudad viene expulsando a los inmigrantes a demandar lotes de tierras en las áreas periféricas de Huancayo para la construcción de sus viviendas.

En la Comunidad Campesina de Miluchaca el factor interno que viene propiciando el mercado de tierras es la necesidad económica y la fuerte emigración de los propios lugareños. Estas tierras para entrar al mercado, entraron al desmembramiento y formalización en las instancias de las notarías y el Registro Público de la ciudad de Huancayo, quedando expeditos para poder vender a los que demandan comprar, así la confianza llega para los demandantes y ofertantes, pero los predios subieron de precio.

\section{Referencias}

Bauer, C. (2003). Activos líquidos: derechos de aguas, mercados de aguas y consecuencias para los mercados de tierras rurales. En Mercados de tierras agrícolas en América latina y el Caribe: una realidad incompleta. Chile: CEPAL.

Carrera, J. (2000). El estudio de mercado de tierras en Guatemala. Santiago de Chile: CEPAL.

Cepes. (2008). Los derechos de propiedad sobre la tierra en comunidades campesinas. Lima, Perú: CEPES.

De Soto, H. (2000) El misterio del capital. Lima, Empresa Editora el Comercio S. A.

Díaz, J. (2016) La renta diferencial de la tierra y la degradación del suelo.

FAO. (2012). Dinámica del mercado de la tierra en América Latina y el Caribe. Roma, Italia: FAO. 
Gonzales de Olarte. (1986) Economía de la comunidad campesina. Lima, IEP.

González, F. (2018) El mercado de tierras en la interfase rural-urbana. Anuario de la Divison Geográfica 2018.

Gutierrez, F. y Garcia, P. (2016) Acceso a la tierra y derechos de propiedad campesinos. Revista colombiana de antropología.

Huaman, A. (2017) Tierras en pugna. Cambios en la tenencia y el valor de la tierra comunal frente a la expansión del agronegocio del etanol en el valle del Chira, Piura. El caso de la comunidad campesina San Lucas de Colán. Pontificia Universidad Católica del Perú.

Kautsky, K. (1980). La cuestión agraria. s.e

Lima, D. y Ignacio, B. (2016) Mercado de Tierras y Conservación de Suelos: Un Análisis Económico. Instituto Nacional de Tecnología Agropecuaria.

Marcelo, R. (2019) Mercado de tierras y relaciones políticas en la comunidad campesina de Pararín (Ancash). Universidad Nacional Mayor de San Marcos

Palacios, V., Montesillo, J., y Santacruz, E. (s.a). Análisis de mercado de tierras en México. México: CIESTAAM - UACh

Pimentel, N. (2017). Periurbanización y diferenciación en el mercado de suelo urbano en Carayllo. Lima: UNMSM.

Poma, J. (2018) La concentración de la tierra: estudio de caso del valle de Ica. Universidad Continental.

Rojas, R. (1981). Guía para realizar investigaciones sociales. México: Universidad Nacional Autónoma de México.

Vogelgesang, F. (1998). Tierra, mercado y Estado. En perspectiva sobre mercados de tierras rurales en América Latina. Washintong, D.C: BID.

Zegarra, E. (1999). El mercado de tierras rurales en el Perú. Santiago de Chile: CEPAL - ECLAC.

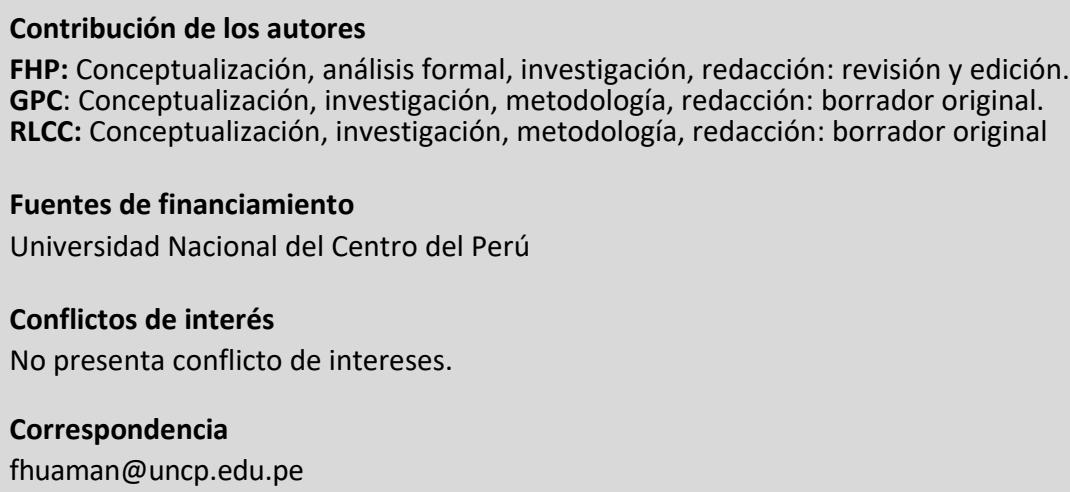

